\title{
PRESENTATION OF ATRIAL SEPTAL DEFECT (ASD) - SYMPTOMS AND SIGNS
}

\author{
HAQUE MS ${ }^{1}$, KHAN HILR ${ }^{2}$, MAHMUD RS ${ }^{3}$

\begin{abstract}
A cross-sectional study was carried out in the National Institute of Cardiovascular Diseases (NICVD), Dhaka, during the period of July, 1992 to June, 1993, which was designed to see the presentation and physical examination findings of atrial septal defect (ASD) patients in our population. A total of 60 ASD patients were included in the study, whose diagnoses were confirmed with echocardiography. Evaluation of the patients showed that $15 \%$ of the patients were asymptomatic and they were detected incidentally. Common symptoms were shortness of breath on exertion (SOBE), Fatigue, palpitation, chest pain and recurrent respiratory infection (RTI). Common physical findings were left parasternal lift, loud first heart sound (S1), fixed splitting of second heart sound (S2) and ejection systolic murmur in pulmonary area. It was observed that all the symptoms and signs in our population correlate well with others.
\end{abstract}

Key words: Atrial septal defect, symptoms and signs, echocardiography.

J Dhaka Med Coll. 2011; 20(1) : 9-11.

\section{Introduction:}

An atrial septal defect (ASD) is a through and through communication between atria at septal level. Symptomatic ASD is uncommon at infancy. ${ }^{1}$ It has been noted that larger the shunt more the cardiac disability. ${ }^{2}$ No or mild symptom in the first three decade of life, patients usually present themselves in their middle age ${ }^{3}$. Its diagnosis depends on symptoms, signs, noninvasive and invasive investigations. Now a days ASD is detected earlier due to the wide use of echocardiography. Atrial septal defect may present with complications like pulmonary hypertension, congestive heart failure and arrhythmia. Besterman $^{4}$ reported pulmonary hypertension in $16 \%$ of his patients. In our country ASD is a common congenital heart disease. During the year 1991, 163 cases were detected by echocardiography in National Institute of Cardiovascular Disease (NICVD), Dhaka. A fair number of studies regarding clinical profile of ASD were done in western world but no such study yet done in our country. Aim of the study is to see the symptoms and sings of ASD patients of our population.

\section{Material and Methods:}

This study was carried out in the national Institute of Cardiovascular Diseases (NICVD),
Dhaka, during the period of July, 1992 to June, 1993. A total of 60 consecutive patients were included who were diagnosed as atrial septal defect (ASD) patients on clinical examination and was confirmed by echocardiography (2D, Doppler and colour flow imaging). Data were collected as per questionnaire. All the data were processed manually.

\section{Results:}

The mean age of the study sample (60 patients) was $22.23 \pm 10.34$ years with range of $5-55$ years. There were 58 ostium secundum type ASD $(96.67 \%)$ and 2 Sinus venosus type of ASD (3.33\%). Of these, 27 were males (45\%) and 33 females $(55 \%)$, a female to male ratio of 1.22:1 (Table-I).

Table-I

Age and Sex distribution of patients $(n=60)$

\begin{tabular}{lccc}
\hline Age & Male & Female & Total \\
\hline $0-10$ & $3(5 \%)$ & $6(10 \%)$ & $9(15 \%)$ \\
$11-20$ & $9(15 \%)$ & $12(20 \%)$ & $21(35 \%)$ \\
$21-30$ & $9(15 \%)$ & $12(20 \%)$ & $21(35 \%)$ \\
$31-40$ & $4(6.67 \%)$ & $2(3.33 \%)$ & $6(10 \%)$ \\
$41-50$ & $1(1.66 \%)$ & $1(1.66 \%)$ & $2(3.33 \%)$ \\
$>50$ & $1(1.66 \%)$ & - & $1(1.66 \%)$ \\
\hline Total & $27(45 \%)$ & $33(55 \%)$ & $60(100 \%)$ \\
\hline
\end{tabular}

1. Dr. Md. Serajul Haque, Senior Consultant, Cardiology, 250 bedded Hospital, Chandpur.

2. Prof. H I Lutfur Rahman Khan, Professor of Cardiology, Dhaka Medical College, Dhaka.

3. Prof. Razia Sultana Mahmud, Ex-Professor of Cardiology, National Institute of Cardiovascular Diseases (NICVD), Dhaka.

Correspondence : Dr. Md. Serajul Haque, Senior Consultant, Cardiology, 250 bedded Hospital, Chandpur. 
Considering the various manifestations it was found that shortness of breath on exertion (SOBE) was observed in $46(76.66 \%)$ patients, fatigue in 34 (56.66\%) patients. Palpitation was complained by $36(60 \%)$ patients. History of non specific chest pain was present in $43.33 \%$ and history of recurrent RTI in $40 \%$ patients. Both orthopnoea and paroxysmal nocturnal dysponea (PND) was complained by $62.66 \%$ patients. Arthalgia, vertigo, syncope, swelling of legs and haemoptysis were rare complaints $(1.66 \%)$. Nine $(15 \%)$ patients were asymptomatic and were diagnosed incidentally (Table-II).

Table-II Symptoms of patients $(n=60)$

\begin{tabular}{llc}
\hline Symptoms & Number $(\%)$ \\
\hline 1. & SOBE & $46(76.66 \%)$ \\
2. Fatigue & $34(56.66 \%)$ \\
3. Palpitation & $36(60 \%)$ \\
4. Chest pain & $26(43.33 \%)$ \\
5. Recurrent RTI & $24(40 \%)$ \\
6. Orthopnoea & $4(6.66 \%)$ \\
7. PND & $4(6.66 \%)$ \\
8. No symptom & $9(15 \%)$ \\
\hline
\end{tabular}

According to New York Heart Association (NYHA) classification, most of the patients $(68 \%)$ in the study were in class II. None were in class IV. Fifteen percent were in class I and $16.66 \%$ in class III. (Table-III).

Table-III

Functional status of patients $(n=60)$ (NYHA Classification)

\begin{tabular}{lccc}
\hline Class I & Class II & Class III & Class IV \\
\hline $9(15 \%)$ & $41(68.33 \%)$ & $1016.66 \%)$ & - \\
\hline
\end{tabular}

No patients had manifestation of cyanosis, clubbing, oedema or significant retardation of growth. Tachycardia was found in $18(30 \%)$ cases, irregular pulse in $3(5 \%)$, prominent ' $a$ ' wave in JVP in $12(20 \%)$ and prominent ' $v$ ' wave in $2(3.33 \%)$ of cases. Chest deformity was detected in 27 (45\%) and apex beat was shifted in $22(36.66 \%)$ cases. On auscultation 46 $(76.66 \%)$ cases had loud $1^{\text {st }}$ heart sound (S1) in tricuspid area and fixed splitting of $2^{\text {nd }}$ heart sound (S2) was found in $58(96.66 \%)$ cases. Pulmonary $2^{\text {nd }}$ heart sound (P2) was loud in 15 $(25 \%)$ cases. Ejection systolic murmur (ESM) was present in pulmonary area in 57 (95\%) cases. Mid diastolic murmur (MDM) was present in $11(18.33 \%)$ cases in tricuspid area. In the left parasternal area early diastolic murmur was present in $8(13.33 \%)$ cases. Apical pan systolic murmur (PSM) was present in $5(8.33 \%)$ of cases ( Table-IV).

\section{Table-IV}

Signs Found in patients $(n=60)$

\begin{tabular}{llc}
\hline Signs & & Number (\%) \\
\hline 1. & Regular pulse & $39(65)$ \\
2. & Tachycardia & $18(30)$ \\
3. & Irregular pulse & $03(05)$ \\
4. & Prominent 'a' wave in JVP & $12(20)$ \\
5. & Prominent 'v' wave in JVP & $02(3.33)$ \\
6. & Chest deformity & $27(45)$ \\
7. & Shifted apex beat & $22(36.66)$ \\
8. & Systolic thrill & $02(3.33)$ \\
9. & Left parasternal lift & $45(75)$ \\
10. & Loud first heart sound & $46(76.66)$ \\
11. & Loud P2 & $15(25)$ \\
12. & Fixed splitted S2 & $58(96.66)$ \\
13. & ESM & $57(95)$ \\
14. & PSM & $05(8.33)$ \\
15. & MDM & $11(18.33)$ \\
16. & EDM & $08(13.33)$ \\
\hline
\end{tabular}

Discussion:

Atrial septal defect is a common heart disease. They may be asymptomatic ${ }^{5,6}$. In this study, $15 \%$ patients were asymptomatic. They were detected incidentally. The incidence of asymptomatic patients was almost similar to that reported by Markman et al. ${ }^{7}$ In the present study, $m$ the commonest age of presentation was second and third decade, which confirms with that of Arnfred's study ${ }^{8}$. In the present study, the patients presented between 5 and 
55 years, which correlates well with Forefang et al. ${ }^{6}$. This study also confirms that female are more affected $9,10,11$.

The common complaints of the patients was shortness of breath on exertion, palpitation, fatigue recurrent repiratory tract infection and chest pain which correlates with previous study in this field. ${ }^{6,7}$. On physical examination, common findings were chest deformity, left parasternal lift, shifted apex beat, loud first heart sound .wide fixed splitting of second heart sound and ejection systolic murmur in pulmonary area which correlates well with Mark $^{5}$ and Arnfred 7 . Prominent 'a' wave in JVP was found in $20 \%$ of patient in this study, Besterman ${ }^{4}$ found Prominent ' $a$ ' wave in 5 patients out of total 41 . Loud P2 found in 25\% of patient of this study. Harries ${ }^{12}$ reported that loud P2 may occur in normal health but he also advocated the consideration of pulmonary hypertension in presence of loud P2; ejection systolic murmur is also a common finding. Harvey ${ }^{13}$ suggested that the simple combination of wide splitting of S2 with systolic murmur over pulmonary area or along left sternal border offers an immediate clue to atrial septal defect. Mark $^{5}$ and Arnfred ${ }^{7}$ suggested that MDM may occur in large shunt, they also mentioned that EDM may occur in increased pulmonary artery pressure.

\section{References:}

1. Hunt CE, Lucus RV Jr. Symptomatic atrial septal defect in infancy. Circulation 1973; 67: 1042.

2. Beller BM, Dexter L. Clinical and Haemodynamic stability in patients with a large atrial septal defect. JAMA 1966; 95: 180.
3. Vogelpoel SV. Atrial septal defect. Am Heart J 1964; 68: 263-77.

4. Besterman E. Atrial septal defect with pulmonary hypertension. Br Heart J 1961; 23: 587.

5. Mark H. Natural history of Atrial septal defect with criteria for selection for surgery. Am J Cardiol 1963; 12: 66 .

6. Forefang K, Simosen S, Andersen A and Efskind L. Atrial septal defect of secundum type in middle age, clinical result of surgery and correlations between symptoms and haemodynamics. Am Heart J 1977; 94: 44.

7. Markman P, Howitt G and Wade EG. Atrial septal defect in the middle aged and elderly. Quart $\mathrm{J}$ Med 1965; 34: 409.

8. Arnfred E. Symptoms, signs and haemodynamics in one hundred cases of atrial septal defect confirmed by operation. J Cardiovas Surg 1966; 7: 349 .

9. Dalen JE, Haynes FW and Dexter L. Life expectancy with atrial septal defect. JAMA 1967; 200: 112 .

10. Dave SK, Pakrashi CB, Wooler HG, Ionescu MI. Atrial septal defect in adults, clinical and hemodynamic result of surgery. Am J Cadiol 1973; 31: 7 .

11. Wood P, Mc Donald L and Emanuel R. The clinical picture correlated with physiological observations in the diagnosis of congenital heart disease. Pediatr Clin North America 1958; 5: 981.

12. Harries A. The second heart sound in health and in pulmonary hypertension. Am Heart J 1970; 79: 145.

13. Harvey WP. Oscultatory features. In: Roberts WC. ed. Adult congenital heart disease. $1^{\text {st }}$ ed. Philadelphia: FA Davies Co; 1987: p. 133. 